Revista do Corpo Discente do Programa de Pós-Graduação em História da UnB

Em TEMPO dE HISTÓRIAS | Brasília-DF | n. 37 | p. 3-8 | jul./dez. 2020.

ISSN 2316-1191

DOI: $10.26512 /$ emtempos.v1i37.35413

\title{
Apresentação do Dossiê História \& Cinema
}

O dossiê História e Cinema reúne trabalhos que tematizam o cinema com base em diferentes aportes teórico-metodológicos, buscando pensar o filme como documento histórico que deve ser interrogado a partir da especificidade da linguagem cinematográfica, da história do cinema, das tradições cinematográficas e do contexto histórico e cultural de produção, assim como das formas de circulação e consumo das imagens. Assim, o dossiê contém artigos que investigam a circulação de memórias hegemônicas ou subterrâneas, do imaginário social e político em diferentes gêneros, ficção ou documentário, animação ou série televisiva, e em diferentes suportes, películas ou digital. Também apresenta pesquisas que situam as discussões sobre a historiografia do cinema e o mercado cinematográfico.

Organizamos o dossiê em séries temáticas, buscando aproximar os trabalhos a partir de temas ou metodologias de abordagem comuns. A primeira série de artigos versa sobre as questões que envolvem o debate sobre as relações étnico-raciais, com destaque para o racismo e a produção de imagens estereotipadas das subjetividades constituídas na diáspora africana, seja no cinema brasileiro, seja no cinema estadunidense. Como contraponto a essas imagens, o artigo $A$ Colonialidade $e$ a Emancipação no filme Emitai de Sembène Ousmane (Senegal, Anos 1970), de autoria de Vinícius Pinto Gomes, analisa o filme Emitai (1971), dirigido por Sembène Ousmane, a partir de um diálogo com os estudos pós-coloniais e decoloniais, buscando uma perspectiva africana sobre as lutas contra a dominação colonial em África. Além do filme, o autor apresenta um rico corpus documental constituído por entrevistas do diretor e cartazes do filme produzidos em diferentes países. Renata Barbosa Melo do Nascimento analisa As representações do continente africano no cinema através dos filmes Hotel Ruanda (2004) e O último Rei da Escócia (2006), ancorada nos estudos decoloniais, buscando apreender as confluências entre as obras quanto às imagens e lugares atribuídos às populações do continente africano e desvendando conexões históricas e culturais na produção de imagens eurocêntricas estereotipadas sobre o continente africano.

Vanessa de Araújo Andrade, no artigo $E$ o Vento Levou: cinema, racismo $e$ silenciamento sobre a abolição da escravatura na Guerra Civil dos Estados Unidos, analisa a intertextualidade entre o livro que deu origem ao filme clássico de 1939, os silêncios sobre o tema da abolição da escravatura nos EUA e a questão racial advinda da libertação dos escravizados. O artigo de Leonardo Bentes Rodrigues, Colonialismo como laboratório: "A Batalha de Argel" e a tortura como projeto de controle politico, problematiza a relação do cinema com o processo de descolonização através do filme do diretor Gilles Pontecorvo de 1965, traçando vínculos entre as experiências de tortura nas colônias francesas e a consolidação de seu uso como controle político nos regimes 
Revista do Corpo Discente do Programa de Pós-Graduação em História da UnB

Em TEMPO dE HISTÓRIAS | Brasília-DF | n. 37 | p. 3-8 | jul./dez. 2020.

ISSN 2316-1191

autoritários na segunda metade do século XX. A circulação de memórias sobre o movimento negro estadunidense é analisada em El movimiento negro estadounidense y las batallas por la memoria: una mirada desde The Boondokcs, das autoras Tereza Maria Spyer Dulci e Vania Macarena Alvarado Sadivia. Partindo da premissa de que os produtos audiovisuais são lugares privilegiados para as "batalhas da memória", as autoras analisam os principais marcos do movimento negro estadunidense e a criação e recriação de memórias presentes no quadrinho The Boondokcs (1996), e na série de animação The Boondokcs (2006), do criador Aaron McGruder.

Nessa primeira série, também encontramos os trabalhos de ensino e pesquisa realizados a partir do cinema brasileiro. O artigo Cinema, história e educação: racismo e ensino de História em $O$ Assalto ao Trem Pagador, dos autores Jairo Carvalho do Nascimento e Genilson Ferreira da Silva, analisa o filme O Assalto ao Trem Pagador (1962), de Roberto Farias, em duas perspectivas: buscando evidenciar e problematizar questões raciais presentes no filme e sua relação com o seu contexto de produção, bem como apresentar as possibilidades pedagógicas para o ensino de História no Ensino Médio em cumprimento à lei 10639. O artigo O filme Quilombo: uma outra história negra, de Rafael Garcia Madalen Eiras, analisa o filme Quilombo (1984), do diretor Carlos Diegues, relacionando o tratamento da escravidão no filme, a história do cinema brasileiro nos anos 1970/80, a revisão historiográfica sobre a história da escravidão e as questões pautadas pelo movimento negro no contexto da redemocratização brasileira. Bárbara Brognoli Donini, em O filme que sai do armário: o Cinema Lésbico a partir da obra de Adelia Sampaio, analisa o longa de ficção Amor Maldito (1984), da cineasta afrobrasileira Adelia Sampaio que versa sobre o amor lésbico, como marco na criação de um Cinema Lésbico no Brasil.

Fechando a série, o trabalho de Janailson Macêdo Luiz, Estou aqui fazendo um filme: relações étnico-raciais e lutas pela memória em Osvaldão (2014), aborda o documentário dos diretores Vandré Fernandes, Ana Petta, Fábio Bardella e André Lorenz Michiles, que narra a história de Osvaldo Orlando da Costa, um dos mais conhecidos personagens da Guerrilha do Araguaia (1972-1974). O autor problematiza as representações sobre a história de vida do guerrilheiro e a tematização das relações raciais, situando o filme nos debates historiográficos mais recentes sobre o regime militar e a questão racial.

A segunda série temática trata das relações entre cinema e memória e cinema e propaganda em regimes autoritários, por meio da ficção, do documentário, do cinejornal e do filme de propaganda. Vinícius Alexandre Rocha Piassi, em Hoje (2011) e Trago Comigo (2016): imagens da estranha alteridade do passado, analisa filmes da cineasta Tata Amaral que problematizam o passado autoritário da ditadura militar e o prolongamento de traumas no presente democrático. Vinícius Viana Juchem, no artigo Cinema na ditadura militar: uma análise do filme A freira e a tortura (1984), aborda o filme dirigido por Ozualdo R. Candeias, relacionando a produção cinematográfica da Boca do Lixo e o seu gênero mais famoso, a pornochanchada, e os atos de censura da ditadura militar. Beatriz Costa Barreto e Marília Romero Campos, em O que pode o cinema? História e política em Cabra marcado para morrer (1984) de Eduardo Coutinho, examinam a potência do cinema e a sua relação com a história, a política e a memória. 
Revista do Corpo Discente do Programa de Pós-Graduação em História da UnB

Em TEMPO DE HISTÓRIAS | Brasília-DF | n. 37 | p. 3-8 | jul./dez. 2020.

ISSN 2316-1191

Andrei Chirilã, em $O$ documentário Dzi Croquettes (2009) e a construção de uma memória marginal, do subterrâneo e do esquecimento sobre a contracultura na ditadura civil-militar no Brasil, aborda o documentário da diretora Tatiana Issa como elemento de resgate de uma memória na historiografia da contracultura na década de 1970, e como esta memória monumentalizada ignora os elementos conjunturais que permitiram a criação do Dzi Croquettes, além de, anacronicamente, construir o grupo teatral como a origem do movimento homossexual no Brasil.

Isadora Dutra de Freitas, no artigo Cinejornalismo em perspectiva histórica: trajetória e usos políticos no Brasil, analisa os usos políticos dos cinejornais em diferentes contextos históricos: Estado Novo a partir do Cinejornal Brasileiro, o período democrático e o Cinejornal Bandeirante da Tela, e os cinejornais da ditadura militar. Alvaro Eduardo Trigueiro Americano e Letícia Barbosa Torres Americano, em Disciplina e ordem nas telas do Cine Jornal Brasileiro: os "sócios" do poder no Estado Novo, investigam a relação entre as Forças Armadas e o Estado Novo através da propaganda política nas edições do Cinejornal Brasileiro (1938-1946). Rebecca Ferreira Dias, em Perseguidos pela Nação, exaltados pelo Cinema: o comunismo em A Revolução de Maio, identifica as representações do comunismo no filme $A$ Revolução de Maio, dirigido por António Lopes Ribeiro - o cineasta do Estado Novo português - e lançado em 1937.

$\mathrm{Na}$ terceira série, encontramos trabalhos que problematizam a relação entre cinema e cidade a partir da análise de documentários e cinejornais. Leila Saads, em Cinema e memória urbana: documentário Estrutural e narrativas sobre a consolidação da Cidade Estrutural - DF, tece narrativas possíveis sobre a formação da Cidade Estrutural a partir do diálogo entre o filme de Webson Dias, lançado em 2016, e a produção acadêmica sobre essa ocupação urbana, para compreender as disputas políticas e territoriais representadas no documentário e as imagens de cidade que emergem a partir dessas representações. Cristiane de Assis Portela e Anna Lorena Morais Silva, em Enunciando Contra-Hegemonias: Narrativas Candangas de Vaqueiros Voadores, analisam a narrativa do documentário Romance do Vaqueiro Voador, de Manfredo Caldas (2007), que rememora a construção de Brasília sob a perspectiva de trabalhadores que a edificaram. A película é baseada em poema-cordel homônimo, de autoria de João Bosco Bezerra Bonfim, e pode ser entendida como um contraponto aos discursos tornados hegemônicos nas narrativas sobre o Distrito Federal.

Alisson Oliveira Soares de Santana e Luís Vitor Castro Júnior, em CorpoCidade: uma análise do Filme "Um Crime Na Rua", de Olney São Paulo, discutem o curta-metragem Um Crime na Rua (1955), de Olney São Paulo, gravado no centro da cidade de Feira de Santana, Bahia, refletindo sobre as experiências e as diversas manifestações dos corpos no espaço urbano. Vinícius da Cunha Bisterço, em Utopia e destruição, ruína e progresso: a condição de marginalidade social no filme A Margem (1967), de Ozualdo Candeias, problematiza a construção da experiência dos marginalizados no filme e sua perspectiva crítica acerca do processo de modernização da cidade de São Paulo intensificado a partir dos anos 1950.

$\mathrm{Na}$ quarta série apresentamos os trabalhos que propõem uma reflexão sobre a narrativa cinematográfica e a narrativa histórica. Yuri Leonardo Rosa Stelmach e Lúcio 
Revista do Corpo Discente do Programa de Pós-Graduação em História da UnB

Em TEMPO DE HISTÓRIAS | Brasília-DF | n. 37 | p. 3-8 | jul./dez. 2020.

ISSN 2316-1191

Geller Junior, no artigo $O$ príncipe e o poeta: o passado russo e transcaucásio pelas lentes de Sergei Eisenstein e Parajanov, abordam os filmes produzidos na União Soviética, Alexander Nevsky (1938), de Sergei Eisenstein, e A Cor da Romã (1969), de Sergei Parajanov, e discutem como os passados russo e transcaucásio são construídos pelos cineastas e como tais narrativas se aproximam da escrita histórica. Vanda Fortuna Serafim e Gabriella Bertrami Vieira, em Filmar é escutar: história, documentário e a escuta sensivel da alteridade em Santo forte (1999), relacionam as práticas do cinema documentário e a prática historiográfica a partir dos conceitos de "alteridade" e "sensibilidade", discutidos por Sandra Pesavento e François Hartog. Bruno José Yashinishi, no artigo A relação Cinema-História: fundamentos teóricos e metodológicos, procura elucidar a possível relação entre narrativa histórica e narrativa cinematográfica, compreendendo que ambas são capazes de organizar o conhecimento e a consciência histórica.

Barbara Mangueira do Nascimento, em Imagem, montagem e história em Videogramas de uma Revolução de Harun Farocki e Andrei Ujică, propõe a análise do filme Videogramas de uma Revolução (1992), de Harun Farocki e Andrei Ujică, a partir da relação entre imagem, montagem e história, e da problematização das noções de tempo histórico.

A quinta série de artigos é composta por trabalhos que tratam o sertão como um tema recorrente na história do cinema brasileiro. Marcelo Fidelis Kockel, em História, sertão e devir-sensível em Cinema, aspirinas e urubus, propõe analisar as construções discursivas sobre o sertão, a história e o devir-sensível dos personagens que aparecem ao longo do filme Cinema, aspirinas e urubus (2005), do diretor Marcelo Gomes. O autor compreende o filme como o próprio acontecimento, singular na sua materialidade sensível, modulada, e não um enunciado de reconhecimento sobre algo que lhe antecede.

A partir de outra perspectiva teórica, Diogo Cavalcanti Velasco, em Áridos Movies: o encontro da metodologia de Pierre Sorlin com o cinema sertanejo nordestino autóctone, examina como, nos anos 2000, novas correntes de representação cinematográfica, em especial o grupo de cineastas do Nordeste, Marcelo Gomes, Lírio Ferreira, Paulo Caldas e Karim Ainouz, passam a produzir novas asserções sobre o sertão, ressignificando-o de acordo com um mundo contemporâneo globalizado, característico daquele contexto histórico. Daniel Ferreira da Silva, em O minimalismo absurdo na animação Morte e Vida Severina de Afonso Serpa, analisa a estética minimalista do Teatro do Absurdo empregada para transformar a peça-poema Morte $e$ Vida Severina em animação cinematográfica 3D, focando em elementos sonoros e cores monocromáticas que universalizam o sertão através do sentimento de espanto, da sensação de silêncio e vazio e de uma monotonia existencial.

A sexta série é constituída por trabalhos que privilegiam a análise da música e da intertextualidade presente em diferentes gêneros. Hellen Silvia Marques Gonçalves, em O Jazz como Elemento Catalisador da Tragédia Grega, segundo Friedrich Nietzsche, no Filme Crise (1945) de Ingmar Bergman, analisa a música como elemento narrativo de destaque no filme do cineasta sueco. Felipe Nascimento de Araujo, em $A$ Música Antiga como elemento narrativo no cinema: uma análise dos coros gregos em Electra, a Vingadora (1962) e Hércules (1997) da Disney, aborda o uso das performances musicais 
Revista do Corpo Discente do Programa de Pós-Graduação em História da UnB

EM TEMPO DE HISTóRIAS | Brasília-DF | n. 37 | p. 3-8 | jul./dez. 2020.

ISSN 2316-1191

antigas através dos coros gregos como elemento narrativo no cinema em gêneros distintos, relacionando tais obras ao seu contexto social de produção. Franco Santos Alves da Silva, em Pink Floyd - The Wall: uma distopia do auto isolamento no longametragem de 1982, analisa a intertextualidade entre o disco The Wall (1979) e o filme Pink Floyd The Wall (1982), com destaque para o papel fundamental da música na construção de uma narrativa distópica.

A sétima série trata das possibilidades pedagógicas do cinema na formação de professores e na História Pública. Luis Fernando Cerri e Rosângela Maria Silva Petuba, em $A$ operação do filme na formação de professores de História: uma experiência em licenciatura na UEPG (2016-2018), apresentam a experiência de formação de professores por meio da análise histórica e didática de filmes fundamentada nos métodos ativos e na abordagem dos filmes como fontes históricas a serem estudadas por professores e aluno. Josias José Freire Júnior, em História pública e cultura histórica na produção audiovisual contemporânea, problematiza significados das narrativas audiovisuais veiculadas pela série televisiva Guia Politicamente Incorreto (2017), em articulação com as discussões da História Pública, da didática histórica e da cultura histórica.

A oitava série é composta por trabalhos que tematizam a elaboração da memória e do passado a partir do estudo comparado entre filmes. Yuri Barbosa Resende, em Oscar Wilde vai ao cinema: a construção da imagem do dândi em 'Wilde' (1997) e 'Velvet Goldmine' (1998), discute a construção da imagem de Oscar Wilde realizada por dois filmes de gêneros distintos: a cinebiografia 'Wilde' (1997) e o drama musical 'Velvet Goldmine' (1998). Monaliza Caetano dos Santos, em Um vácuo construído sobre um vazio": cinema alemão oriental e o conflito geracional a respeito do passado, analisa as tensões entre pais e filhos, na Alemanha Oriental, em torno da colaboração com o nazismo na Segunda Guerra Mundial, representadas em dois filmes produzidos na Alemanha Oriental, em 1968 e 1971. Andreza Santos Cruz Maynard, em Luta honrosa ou infernal? A Segunda Guerra Mundial a partir dos filmes KV-1: Almas de ferro (2018) e A Passagem (2019), analisa como um filme russo e um filme italiano recentes abordam a Segunda Guerra Mundial, observando como constroem a participação dos seus respectivos países de origem no conflito.

$\mathrm{Na}$ nona série, temos trabalhos que tratam da construção do feminino em um filme épico e em um filme bíblico. Ramiro Paim Trindade Junior, em Conservadorismo no Cinema dos anos 1980: análise do Filme "Excalibur, a Espada do Poder", discute as representações dos(as) protagonistas no filme Excalibur, a Espada do Poder (1981), relacionando as construções negativas das protagonistas femininas ao conservadorismo estadunidense vigente no contexto de produção do filme. Talita Von Gilsa, em Maria Madalena no cinema: os filmes épicos bíblicos e a cinebiografia de 2018, analisa a representação de Maria Madalena nos filmes épicos bíblicos, O Rei dos Reis (1961) e A Maior História de Todos os Tempos (1965) e na cinebiografia Maria Madalena (2018), dirigida por Garth Davis.

A décima série versa sobre pesquisas que investigam o mundo do trabalho e as lutas políticas no século XX, e na contemporaneidade. Maurício Knevitz e Alexandre Moroso Guilhão, em Anarquismo, conciliação e conflito em La Patagonia Rebelde (1974), 
Revista do Corpo Discente do Programa de Pós-Graduação em História da UnB

Em TEMPO dE HISTÓRIAS | Brasília-DF | n. 37 | p. 3-8 | jul./dez. 2020.

ISSN 2316-1191

propõem um debate sobre o filme La Patagonia Rebelde (1974), dirigido por Héctor Olivera, baseado em um livro de Osvaldo Bayer, articulando as lutas dos trabalhadores no contexto histórico de produção do filme e os estudos sobre o anarcossindicalismo na Argentina. Cíntia Medina e Adriano Parra, em $O$ fetiche da tecno-produtividade digital em Ken Loach: a uberização do trabalho no filme Você não estava aqui, procuram traçar de modo crítico o atual cenário de uberização do trabalho em curso a partir da estética e narrativa do diretor Ken Loach no filme Você não estava aqui (2018).

A décima primeira série reúne trabalhos que tratam do debate teórico sobre a historiografia do cinema, sobre o mercado cinematográfico e as leis de incentivo, e a análise da atuação do cineasta e as condições de produção em contexto histórico específico. Vanessa Helena Montenegro Brito, em El "giro historiográfico" en los estudios sobre el cine: rupturas y continuidades, apresenta um estudo comparativo entre o desenvolvimento da historiografia do cinema anglo-nórdico e a historiografia do cinema na América Latina e alguns trabalhos sobre os diversos caminhos e linhas de pesquisa em voga na mais recente historiografia do cinema na América Latina. Renata Santos Maia e Fernando Rodrigues Oliveira, em Antes e além das telas: economia e mercado cinematográfico em países da América Latina, analisam as relações econômicas e o funcionamento do mercado audiovisual com destaque para o mercado de distribuição de filmes e as disputas desiguais entre o cinema latino-americano e a indústria de Hollywood. Rosiel do Nascimento Mendonça e Sérgio Ivan Gil Braga, em Glauber Rocha e a autonomia relativa do campo artístico: o caso do documentário "Amazonas, Amazonas" (1966), discutem as relações entre o artista engajado politicamente e os poderes instituídos através do estudo da passagem de Glauber Rocha pelo Amazonas visando a realização de um documentário sob encomenda.

Assim, o dossiê cumpre o objetivo de apresentar a potência do campo de investigação História e Cinema.

Profa. Dra. Angela Aparecida Teles

Organizadora 